\title{
VALIDATION OF SATELLITE PRECIPITATION (TRMM 3B43) IN ECUADORIAN COASTAL PLAINS, ANDEAN HIGHLANDS AND AMAZONIAN RAINFOREST
}

\author{
D. Ballari ${ }^{\mathrm{a}, *}$, E. Castro ${ }^{\mathrm{a}}$, L. Campozano ${ }^{\mathrm{b}, \mathrm{c}}$

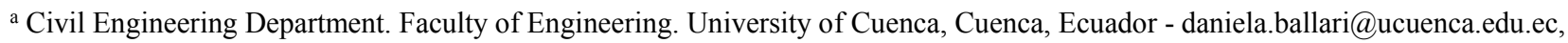 \\ edisson102castro@hotmail.com \\ ${ }^{\mathrm{b}}$ Department of Water Resources and Environmental Sciences. University of Cuenca, Ecuador \\ ${ }^{\mathrm{c}}$ Faculty of Engineering. University of Cuenca, Cuenca, Ecuador - lenin.campozano@ucuenca.edu.ec
}

\author{
Commission VI, WG VIII/4
}

KEY WORDS: TRMM, validation, statistical error metrics, detection indexes, Ecuador, ungagged watershed basins

\begin{abstract}
:
Precipitation monitoring is of utmost importance for water resource management. However, in regions of complex terrain such as Ecuador, the high spatio-temporal precipitation variability and the scarcity of rain gauges, make difficult to obtain accurate estimations of precipitation. Remotely sensed estimated precipitation, such as the Multi-satellite Precipitation Analysis TRMM, can cope with this problem after a validation process, which must be representative in space and time. In this work we validate monthly estimates from TRMM $3 B 43$ satellite precipitation $\left(0.25^{\circ} \times 0.25^{\circ}\right.$ resolution), by using ground data from 14 rain gauges in Ecuador. The stations are located in the 3 most differentiated regions of the country: the Pacific coastal plains, the Andean highlands, and the Amazon rainforest. Time series, between 1998 - 2010, of imagery and rain gauges were compared using statistical error metrics such as bias, root mean square error, and Pearson correlation; and with detection indexes such as probability of detection, equitable threat score, false alarm rate and frequency bias index. The results showed that precipitation seasonality is well represented and TRMM 3B43 acceptably estimates the monthly precipitation in the three regions of the country. According to both, statistical error metrics and detection indexes, the coastal and Amazon regions are better estimated quantitatively than the Andean highlands. Additionally, it was found that there are better estimations for light precipitation rates. The present validation of TRMM 3B43 provides important results to support further studies on calibration and bias correction of precipitation in ungagged watershed basins.
\end{abstract}

\section{INTRODUCTION}

With the growing demand of water resources for agriculture, energy generation and industry, it is extremely important to better understand precipitation behavior. Accurate precipitation data is needed for hydrological models supporting water resource management and climate change studies.

Estimating precipitation is a complicated task in regions, such as Ecuador, with limited rain gauge networks and high spatiotemporal precipitation variability, which is mainly due to the highly complex topography. For this reason, satellite products have become a valuable tool to obtain distributed estimates of precipitation at several scales in time, providing information where rain gauges are not available or when there is not recorded data (Kidd et al., 2011).

The TRMM 3B43 Multi-satellite Precipitation Analysis is one of the most widely used products. It combines precipitation estimates from multiple satellites as well as control rain gauges. This combination from various sensors is what sets this particular product ahead of others of its type (Ceccato and Dinku, 2010). They are freely available in the traditional V6 and updated V7 versions. The spatial resolution is $0.25^{\circ}$ x $0.25^{\circ}(\sim 27 \mathrm{~km} \times 27$ $\mathrm{km})$ with an almost global coverage (50 $0^{\circ}$ latitude band N-S). While temporal resolution is every 3 hours, daily and monthly aggregations are also available. This product is available since January 1998 (Huffman et al., 2007) up to July 2014 when satellite fuel was exhausted (Huffman, 2015).

In Ecuador, satellite products have been used as an important source for climate prediction (Muñoz et al., 2010). However, in order to use these products to its fullest potential, it is imperative to assess it. Therefore, this paper validates monthly precipitation estimates from TRMM 3B43 V7 satellite product on three main regions of Ecuador: the Pacific coastal plains, the Andean highlands and the Amazonian rainforest. TRMM 3B43 V7 is compared with rain gauge data published in the annuals of the National Institute of Meteorology and Hydrology of Ecuador (INAMHI). Version 7 of TRMM 3B43 was used because it has been proved to improve the bias, specifically in the Ecuadorian coastal region (Ochoa et al., 2014) as well as in the AndeanAmazon basin in northern Peru (Zulkafli et al., 2014) with respect to the version 6 of the product. The period of analysis is from 1998, the year since there is available data for TRMM, until 2010, according to INAMHI annuals availability. We selected 14 rain gauges located in the 3 main differentiated regions of the country. Rain gauges selection did not follow a random-representative sampling, instead a small number of them were chosen in order to focus attention in the validation measures. Two types of pixelbased validation measures were selected from the literature (Feidas, 2009; Ochoa et al., 2014; Scheel et al., 2011; Su et al., 2008). The first type is statistical error metrics as bias, root mean squared error and Pearson correlation. The second type is detection indexes as probability of detection, bias index and false alarm rate.

\section{MATERIALS AND METHODS}

\subsection{Rain Gauge Control Data}

Precipitation data from INAMHI rain gauges are available on its website http://www.serviciometeorologico.gob.ec/biblioteca/.

\footnotetext{
* Corresponding author
} 
While records containing monthly data starts in 1990 until 2010, this study ranged from 1998 to 2010 , according to TRMM availability.

Fourteen rain gauges along the Pacific coastal plains, Andean highlands and Amazonian rainforest were chosen, accounting for spatial variability among regions and seasonality representation (Table 1 and Figure 1). Four rain gauges in each region were chosen, except for the Andean highlands where 6 rain gauges were chosen in order to have better representation of mountain terrain. As result, the selected rain gauges showed wide ranges of altitude as well as longitudinal and latitudinal locations.

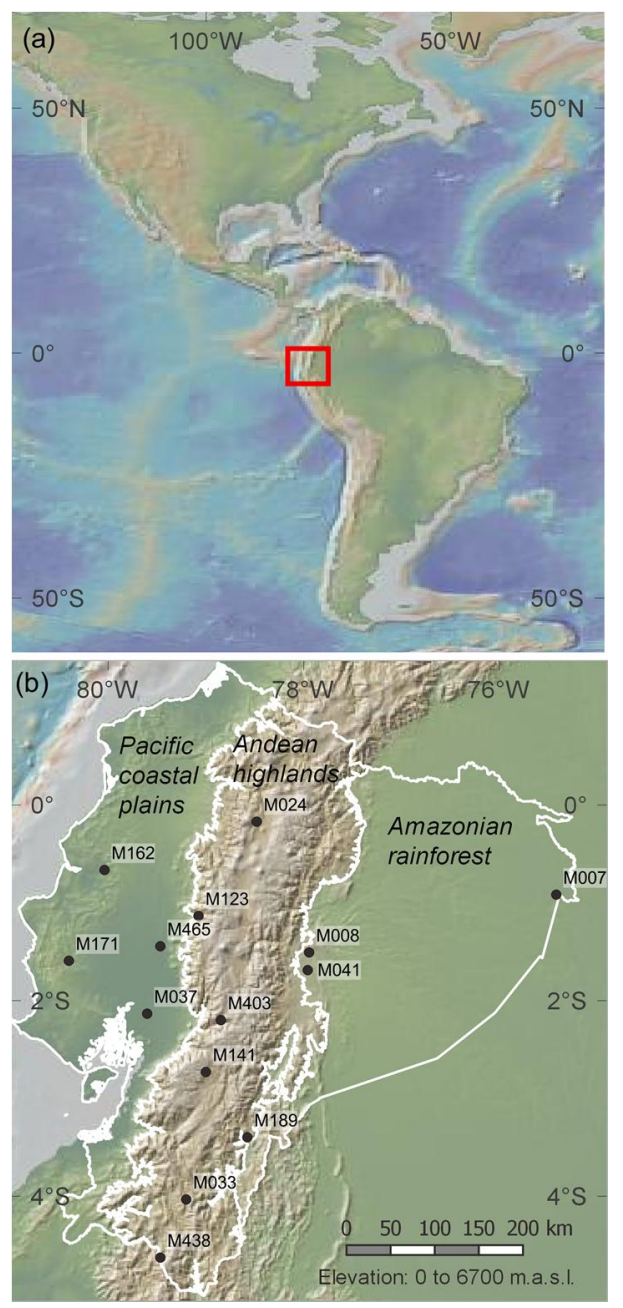

Figure 1. Study area. (a) Ecuador in the American Continent context; (b) Three main regions of study and rain gauges locations

Missing data was checked in order to keep it below a maximum percentage of $20 \%$. Additionally, homogeneity was checked with the RHV4 test, available in the R software, which detects changes in the mean precipitation through time (Wang and Feng, 2004).

\begin{tabular}{|c|c|c|c|c|c|}
\hline Regions & $\begin{array}{l}\text { Rain } \\
\text { gauge }\end{array}$ & $\begin{array}{c}\text { Elevation } \\
\text { (m.a.s.1.) }\end{array}$ & $\begin{array}{c}\text { Longitude } \\
\left({ }^{\circ} \mathrm{W}\right)\end{array}$ & $\begin{array}{c}\text { Latitude } \\
\left({ }^{\circ} \mathrm{S}\right)\end{array}$ & $\begin{array}{l}\text { Missing } \\
\text { data (\%) }\end{array}$ \\
\hline \multirow{4}{*}{ 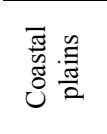 } & M162 & 36 & 80.04 & 0.66 & 2.6 \\
\hline & M465 & 52 & 79.47 & 1.44 & 0.0 \\
\hline & M037 & 13 & 79.60 & 2.13 & 0.0 \\
\hline & M171 & 156 & 80.40 & 1.59 & 1.9 \\
\hline \multirow{6}{*}{ 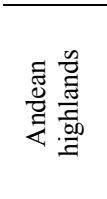 } & M033 & 2160 & 79.20 & 4.03 & 18.6 \\
\hline & M438 & 2100 & 79.46 & 4.63 & 16.0 \\
\hline & M403 & 2267 & 78.84 & 2.20 & 0.6 \\
\hline & M123 & 1471 & 79.07 & 1.13 & 1.9 \\
\hline & M141 & 3260 & 79.00 & 2.73 & 4.5 \\
\hline & M024 & 2812 & 78.48 & 0.17 & 1.9 \\
\hline \multirow{4}{*}{ 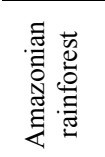 } & M007 & 265 & 75.41 & 0.92 & 0.0 \\
\hline & M008 & 960 & 77.94 & 1.51 & 1.3 \\
\hline & M041 & 880 & 77.95 & 1.69 & 7.7 \\
\hline & M189 & 750 & 78.57 & 3.40 & 1.9 \\
\hline
\end{tabular}

Table 1. Rain gauges description

\subsection{Satellite Product: TRMM 3B43}

The Tropical Rainfall Measurement Mission (TRMM) was launched in November of 1997 to cover the tropic regions (Simpson et al., 1988). One of its products is 3B43 version 7 which combines the results of several sensors and control rain gauges. This product is run once a month to produce the best estimate of precipitation intensity with lower minimum square error. First, 3-hourly estimates of high quality infrared resolution are aggregated on a monthly basis. Next, bias is adjusted by combining the monthly aggregations with rain gauge data using inverse variance weighting (Huffman et al., 2007). The temporal resolution of TRMM $3 \mathrm{~B} 43$ is monthly, while its spatial resolution is $0.25^{\circ} \times 0.25^{\circ}$. It covers the region from $50^{\circ} \mathrm{S}$ to $50^{\circ} \mathrm{N}$ Latitude. More information is available at (NASA, 2014b).

The estimates of monthly rainfall are available for downloading at (NASA, 2014a). Gridded data was downloaded in NCDF format. R software and its spatial packages (gstat, raster, rgeos, and ncdf) were used to intersect images with rain gauges location in order to obtain the satellite time series.

\subsection{Validation Measures}

Averaged monthly precipitation for rain gauges during 1998 2010 were carried out. By comparing the rain gauge and satellite monthly averages, it was possible to ascertain whether the satellite was able to represent seasonality among the three regions of Ecuador. Then rain gauges and satellite time series were compared following a pixel-based approach. This was, precipitation estimates at each rain gauge were compared with satellite estimates at the corresponding grid's pixel. These calculations were performed with $\mathrm{R}$ software, using the hydroGEOF package (Zambrano-Bigiarini, 2014).

\subsubsection{Statistical Error Metrics}

Bias: evaluates the average difference between precipitation estimates made by the satellite product $(\mathrm{S})$ and the rain gauges $(\mathrm{G})$. With $\mathrm{n}$ equal to the number of rain gauges:

$$
\text { Bias }=\frac{1}{n} \sum_{i=1}^{n}\left(S_{X i}-G_{X i}\right)
$$


Root Mean Squared Error (RMSE): compares the estimation errors of the satellite with the rain gauge with an emphasis on extreme values.

$$
R M S E=\sqrt{\frac{1}{n} \sum_{i=1}^{n}\left(S_{X i}-G_{X i}\right)^{2}}
$$

Pearson Correlation Coefficient (r): measures the level of concordance between satellite and rain gauge estimates. Values close to 1 (or -1) represent high correlation.

$$
r=\frac{\operatorname{cov}(S, G)}{\sqrt{\operatorname{var}(S)} \times \sqrt{\operatorname{var}(G)}}
$$

\subsubsection{Detection Indexes}

The accuracy of the satellite detection was analyzed using Probability of Detection (POD), Equitable Threat Score (ETS), False Alarm Rate (FAR) and Frequency Bias Index (FBI) indexes (Schaefer, 1990; Su et al., 2008). They were calculated considering that estimates of TRMM $3 \mathrm{~B} 43$ and rain gauges matched. So that the possibilities for detection could be the following:

- Both the satellite and the rain gauge detect precipitation (a)

- The satellite detects precipitation but the rain gauge does not (b)

- The satellite does not detect precipitation but the rain gauge does (c)

- Both the satellite and the rain gauge do not detect precipitation (d)

Probability of Detection: POD is the fraction of precipitation that was correctly detected. A POD of 1 means a perfect detection from the satellite.

$$
P O D=\frac{a}{a+c}
$$

Equitable Threat Score: ETS is the fraction of precipitation that was correctly detected, but adjusted by the number of detections (He) expected to occur just by chance. $\mathrm{N}$ is the total number of estimates. A perfect satellite detection gives a result of ETS equal to 1 .

$$
\begin{gathered}
E T S=\frac{a-H e}{a+b+c-H e} \\
H e=\frac{(a+c) \times(a+b)}{N}
\end{gathered}
$$

False Alarm Rate: FAR measures the fraction of precipitation detected that were false alarm, which means that the satellite detected it but the rain gauges did not. It measure values between 0 and 1 , where 0 is the perfect value indicating that the satellite did not issue a false alarm.

$$
F A R=\frac{b}{a+b}
$$

Frequency Bias Index: FBI is the ratio between the number of precipitation events detected by the satellite, compared to the number of events detected by the rain gauges. If the index is lower than 1 , means that the satellite is underestimating the precipitation, while higher than 1 indicates overestimation. The range is from 0 to infinity, with a perfect value being 1 .

$$
F B I=\frac{a+b}{a+c}
$$

\section{RESULTS AND DISCUSSION}

\subsection{Rain gauge pre-processing data}

The missing data analysis showed that most rain gauges had less than $3 \%$ of missing data. Only three rain gauges had gaps of 7 , 16 and $18.6 \%$, nevertheless they were still considered acceptable due to the small precipitation observations dataset available (Table 1). Additionally, homogeneity test showed the same tendency in rain gauges.

\subsection{Precipitation seasonality}

Figure 2 shows the seasonality of precipitation from 1998 to 2010 for the coastal plains, the Andean highlands and the Amazon region (in Figures $2 a, 2 b$, and $2 c$, respectively). Rain gauges are shown with solid lines and TRMM with dashed lines. It showed the unimodal rainfall regime for rain gauges located in the coastal and Andes regions, and the bimodal regime for two rain gauges, one located in the Andes and the other in the Amazon region.

Seasonality was well represented qualitatively. That is, although precipitation reported by the satellite over (or under) estimate precipitation, the shape of the graphics was suitable. This happens especially in the Andes and Amazon. In the coastal plains, however, the peak of annual precipitation of satellite estimates was offset one month to the right. In the Andean region, the unimodal regime was well represented qualitatively by the satellite, but the bimodal regime on the M141 rain gauge appeared instead as a unimodal regime (Figure 2.c).

Overall, TRMM 3B43 underestimated precipitation. However, the satellite images overestimated precipitation in 4 rain gauges in the Andes (Figure 2.b and 2.c, M033, M403, M024 and M141) and, only in certain month, in 3 rain gauges in the Amazon (Figure 2.d, M007, M041 and M189).

As previously showed by (Ochoa et al., 2014; Ward et al., 2011) satellite images qualitatively represented precipitation. Although, in terms of quantity, our results showed some differences. According to literature, the TRMM products had shown reasonable performance on monthly basis. In addition, high precipitation rates are generally underestimated while low precipitation rates are overestimated (Habib et al., 2009). These is due to the use of infrared sensors that may underestimate precipitation of low clouds as well as create false alarms because of high but relatively light clouds found at low temperatures (Behrangi et al., 2010). 


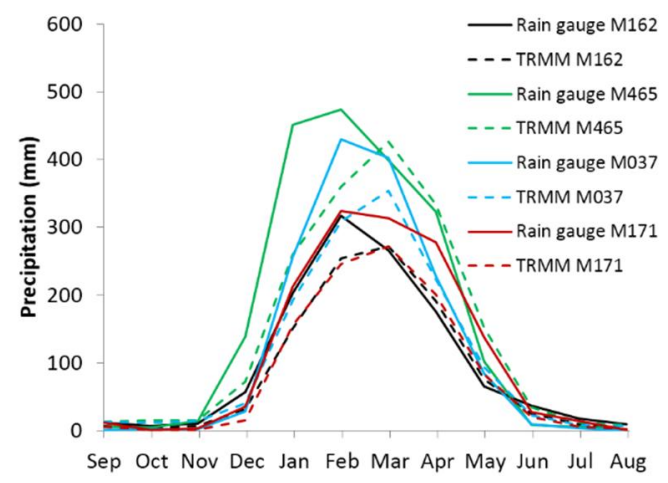

(a) Pacific coastal plains

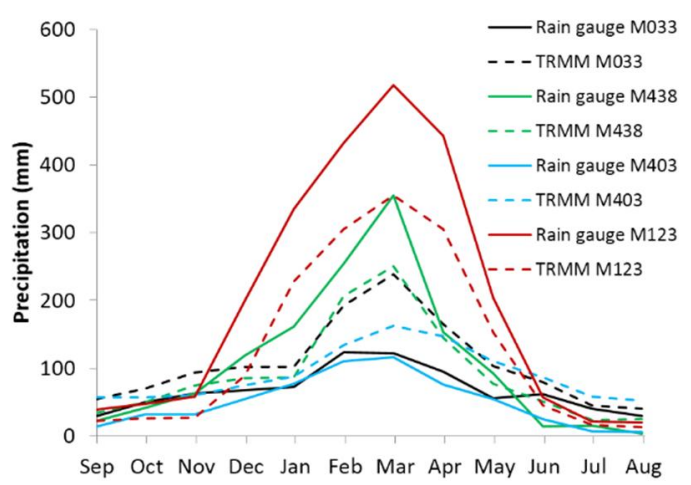

(b) Andean highlands with unimodal regime

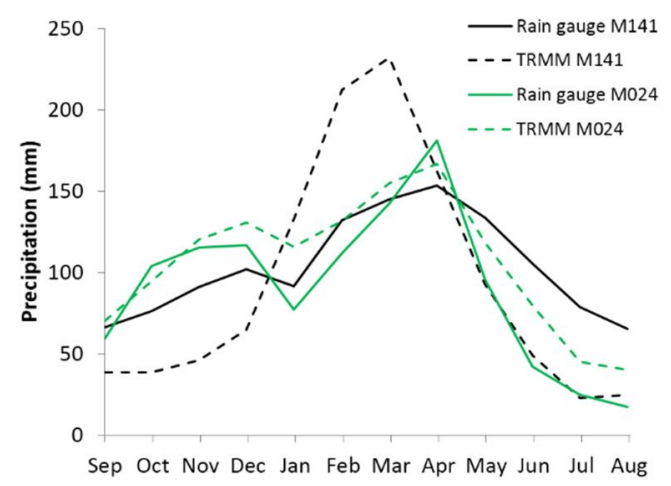

(c) Andean highlands bimodal regime

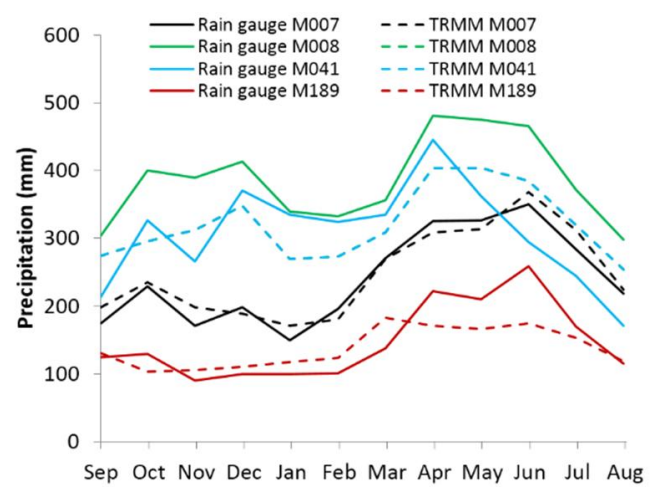

(d) Amazonian rainforest

Figure 2. Precipitation regime representation by mean monthly precipitation estimates of rain gauges (lines) and TRMM 3B43 (dashed). (a) Pacific coastal plains; (b) Andean highlands with unimodal regime; (c) Andean highlands with bimodal regime; and (d) Amazonian rainforest. The results for TRMM-M008 and TRMM-M041 are overlaid to be located on the same TRMM pixel.

\subsection{Statistical error metrics}

Table 2 shows the average statistical error metrics for each region and for Ecuador. Figure 3 shows the respective graphs.

\begin{tabular}{ccccc}
\hline & $\begin{array}{c}\text { Coastal } \\
\text { plains }\end{array}$ & $\begin{array}{c}\text { Andean } \\
\text { highlands }\end{array}$ & $\begin{array}{c}\text { Amazonian } \\
\text { rainforest }\end{array}$ & Ecuador \\
\hline Bias $(\mathrm{mm})$ & 19.43 & 27.89 & 25.28 & 24.20 \\
RMSE (mm) & 88.49 & 76.33 & 68.27 & 77.70 \\
Pearson (-) & 0.90 & 0.75 & 0.78 & 0.81 \\
\hline
\end{tabular}

Table 2. Average bias, RMSE and Pearson correlation coefficient for the 3 studied regions and for Ecuador
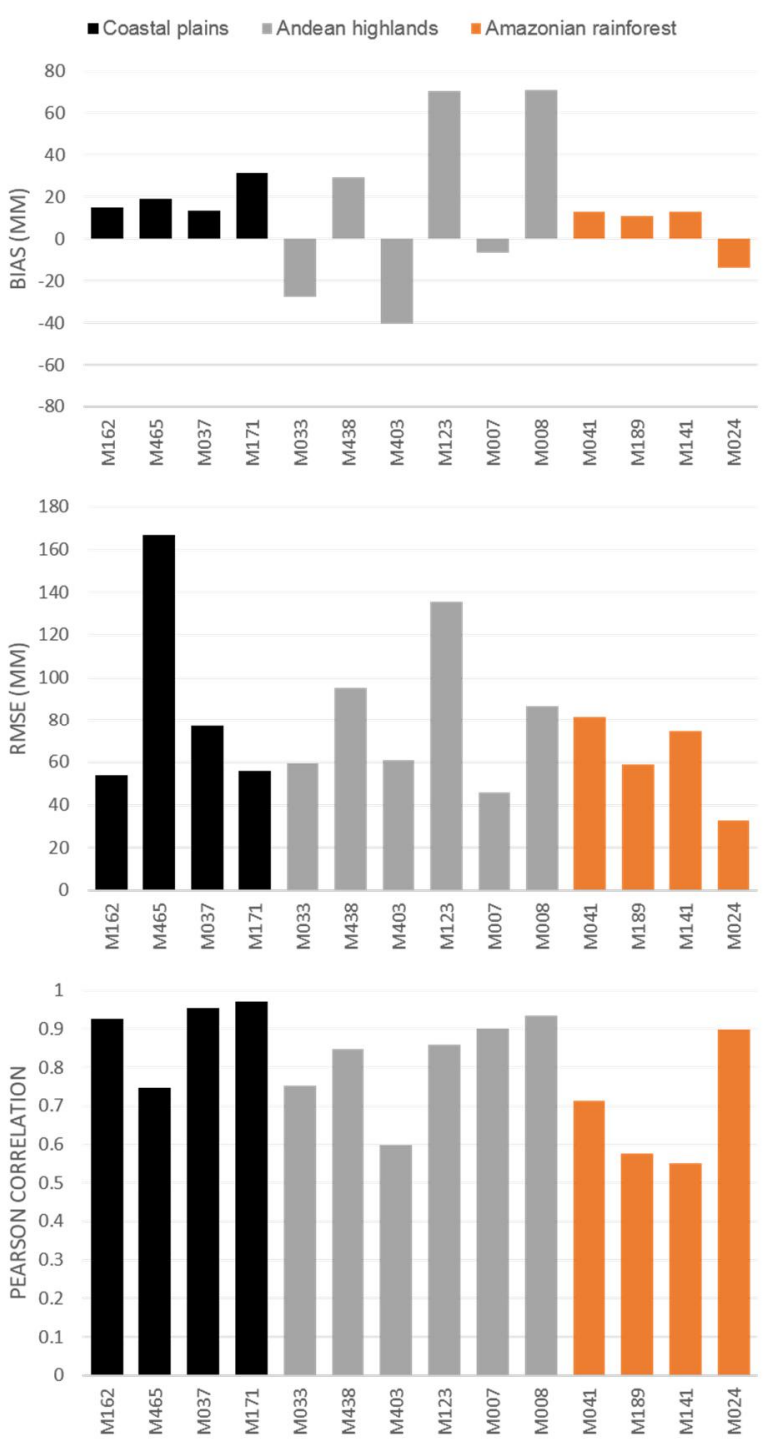

Figure 3. Bias, RMSE and Pearson correlation coefficient for the Coastal plains (black), Andean highlands (grey) and Amazonian rainforest (orange)

There was a moderately high bias for the Andean highlands (28 $\mathrm{mm})$ and Amazonian rainforest $(25 \mathrm{~mm})$, while the lowest bias values were located on the Coastal plains $(19 \mathrm{~mm})$. Rain gauges located at high altitudes (Table 1: altitudes between 960 - 2267 m.a.s.l.) were those with the greatest bias, except for the bimodal regime rain gauges, which, despite being in the highlands (Table 
1: altitudes of 2812 and 3260 m.a.s.1.), had the lowest bias in the region. On average, the bias for Ecuador was $24 \mathrm{~mm}$.

RMSE showed a minimum of $33 \mathrm{~mm}$ at the M024 (Andean bimodal rain gauge) and a maximum of $167 \mathrm{~mm}$ at the M465 (Coastal rain gauge). On average, the RMSE was lower in the Amazon, although there was a small difference with the other regions. In Ecuador, the average was $78 \mathrm{~mm}$ (Table 2).

Pearson correlation ( $r$ ) showed a low correlation value $(0.6)$ in three rain gauges (M403 and M141 of Andean highlands and M189 of Amazonian rainforest). Medium correlation values (between 0.7 and 0.85) were observed in Coastal rain gauges (M162, M037 and M171), Andean highlands (M024) and Amazonian rainforest (M007 and M008). High correlation values (0.9 to 0.96 ) were presented in Coastal plains (M162, M037 and M171), the Andean highlands (M024) and Amazonian rainforest (M007 and M008). On average, the correlation for Ecuador was 0.8 .

For a proper result interpretation, it is needed to analyze all three statistical errors in conjunction with monthly precipitation charts. For instance, at M141 rain gauge, a low bias and RMSE were obtained, but with a very low correlation coefficient. This is due to the fact that the bimodal regime showed by the rain gauge was not captured by the satellite.

Summarizing, it was obtained that the bias was lower on the Coastal plains while the RMSE was lower in the Amazonian rainforest. The Andean highlands had higher bias and RMSE except for the bimodal rain gauge M024. Bimodal rain gauges M007 in the Amazon and M024 in the Andes had minor errors. In addition, it must be stressed that there were high correlation values which confirmed that seasonality was qualitatively well represented.

The results presented in this section are more promising than those obtained in studies performed on a daily scale (Ochoa et al., 2014; Scheel et al., 2011). In fact, these studies showed that TRMM performance improves almost linearly with the temporal aggregation, suggesting that TRMM performs better at monthly rather than a daily or hourly basis. Finally, the TRMM 3B43 seemed to behave better than the TRMM 3B42, since the latter overestimated in all the analyzed rain gauges (Ochoa et al., 2014).

\subsection{Detection indexes}

The Probability of Detection (POD), the Equitable Threat Score Index (ETS), the False Alarm Rate (FAR) and the Frequency Bias Index (FBI) were calculated for different precipitation thresholds of $10,20,50,100,200,300$ and $400 \mathrm{~mm}$. Table 3 shows the mean values for the studied regions.

\begin{tabular}{ccccc}
\hline & $\begin{array}{c}\text { Coastal } \\
\text { plains }\end{array}$ & $\begin{array}{c}\text { Andean } \\
\text { highlands }\end{array}$ & $\begin{array}{c}\text { Amazonian } \\
\text { rainforest }\end{array}$ & Ecuador \\
\hline PDO & 0.79 & 0.75 & 0.84 & 0.79 \\
ETS & 0.60 & 0.21 & 0.36 & 0.39 \\
FAR & 0.13 & 0.33 & 0.09 & 0.18 \\
FBI & 0.91 & 1.26 & 0.90 & 1.03 \\
\hline
\end{tabular}

Table 3. Mean detection indexed for the 3 studied regions and for Ecuador
POD showed that the general tendency of satellite detection decreased when the monthly precipitation also increased (Figure 4). On the Coastal plains and Amazonian rainforest the detection index was greater than 0.8 for thresholds between 100 and 200 $\mathrm{mm}$. In the Andean highlands, POD values greater than 0.8 occurred with precipitation thresholds between 10 and $100 \mathrm{~mm}$. In the Amazonian rainforest, POD presented values greater than 0.92 with precipitation thresholds between 10 and $100 \mathrm{~mm}$. For thresholds greater than $300 \mathrm{~mm}$, POD was reduced to a range between 0.4 and 0.8 . The averaged PDO was greater in the Amazonian rainforest while for Ecuador was 0.8 (Table 3).

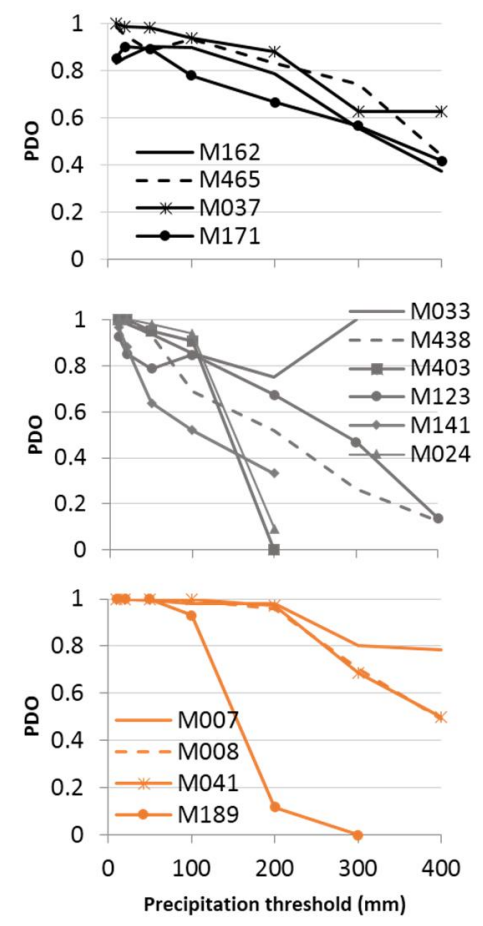

Figure 4. POD for precipitation thresholds of 10, 20, 50, 100, 200, 300 and $400 \mathrm{~mm}$ on the Coastal plains (black), Andean highlands (grey) and Amazonian rainforest (orange)

ETS values were lower than those of POD as they have corrections due to purely random detections (Figure 5). On the Coastal plains, the detection by ETS is better than in the other regions (Table 3). Moreover, according to satellite detection, in all rain gauges ETS values for precipitation increased between 10 and $100 \mathrm{~mm}$ but decreased at $200 \mathrm{~mm}$. There was greater consistency of ETS trend among coastal rain gauges than in the other regions. The average ETS value for Ecuador was 0.4 (Table 3).

FAR showed that, on average, in the Amazonian rainforest the satellite detected fewer false alarms than in other regions (Table 3). Figure 6 shows that on the Coastal plains, the values varied less than in the Amazon. On the coast, FAR was lower when precipitation was recorded between 100 and $300 \mathrm{~mm}$, in the Andes when levels were less than $50 \mathrm{~mm}$, and in the Amazon when they were less than $100 \mathrm{~mm}$. In the Amazon, and in most of rain gauges in the Andes, false alarm increased when precipitation also increased. On average, FAR was 0.2 for Ecuador (Table 3). 


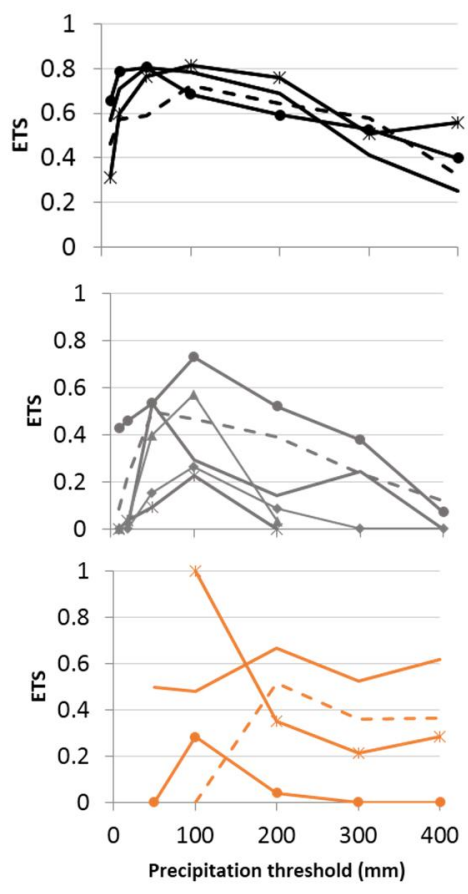

Figure 5. ETS for precipitation thresholds of 10, 20, 50, 100, 200, 300 and $400 \mathrm{~mm}$ on the Coastal plains (black), Andean highlands (grey) and Amazonian rainforest (orange)
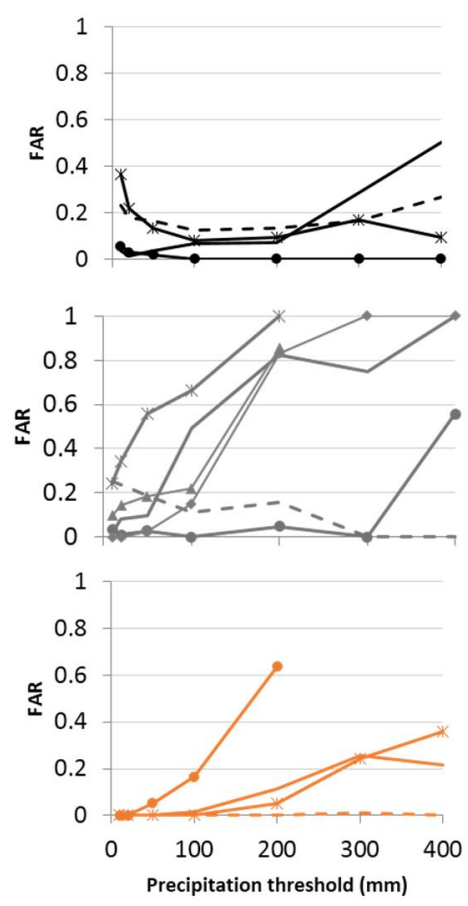

Figure 6. FAR for precipitation thresholds of 10, 20, 50, 100, 200, 300 and $400 \mathrm{~mm}$ on the Coastal plains (black), Andean highlands (grey) and Amazonian rainforest (orange)

Regarding FBI, the tendency to over or underestimate data was variable among the study regions (Figure 7). The precipitation was underestimated by the satellite estimation in most of the rain gauges, however there was a high overestimation in the Andean highlands, reason by which, in Figure 7 the FBI-axis was plotted with a different scale with respect to the other regions. It is important to note that over and underestimation mostly occurred with heavy precipitation (higher than $200 \mathrm{~mm}$ ). Averaged FBI was suitable on the Coastal plains, Amazonian rainforest and for Ecuador as a whole (Table 3).

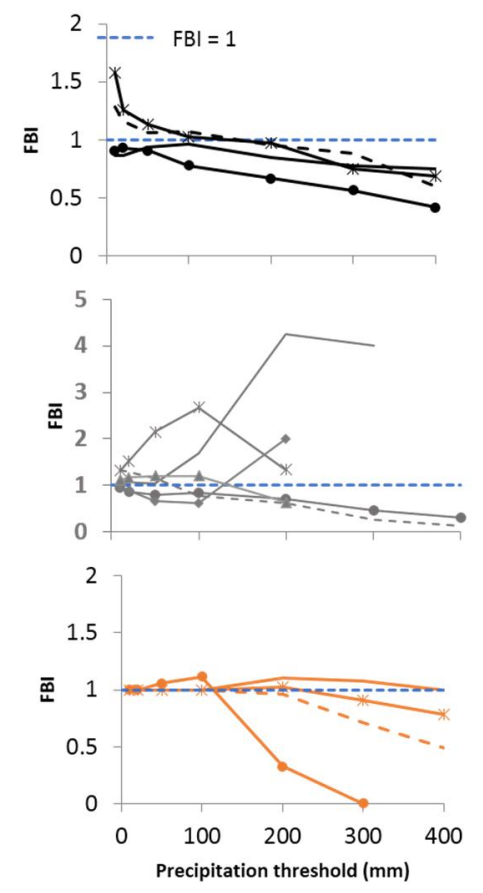

Figure 7. FBI for precipitation thresholds of 10, 20, 50, 100, 200, 300 and $400 \mathrm{~mm}$ on the Coastal plains (black), Andean highlands (grey) and Amazonian rainforest (orange). (FBI axis of the Andean highlands is plotted in a different scale)

\section{CONCLUSIONS}

This study validated monthly TRMM 3B43 precipitation images from 14 INAMHI rain gauges located in the Coastal plains (4 stations), Andean highlands (6 stations) and Amazonian rainforest (4 stations) of Ecuador. In order to seek for a broader representation, a wide range of altitudes and climatic regions were covered. The data was quality controlled by proportionality of nearby stations and homogeneity. It was also verified that the rain gauges had less than $20 \%$ of missing data. Monthly TRMM 3B43 images were obtained and time series extracted at each rain gauge location. Statistical error metrics and detection indexes were used to contrast precipitation from rain gauges and satellite images.

It was found that the precipitation seasonality is qualitatively well represented by the satellite product in Ecuador, in the 3 most differentiated regions of the country. However, TRMM 3B43 satellite precipitation estimates perform better in the Coastal and Amazon regions than in the Andes. Additionally, better satellite results were obtained for light precipitation rates.

The present study has proved that satellite precipitation estimates are a valuable tool, especially for ungagged regions that might be located in complex terrain such as Ecuador. This TRMM 3B43 validation provides important results to support further studies on calibration and bias correction of precipitation in ungagged watershed basins. Additionally, further studies are necessary at more local scales such as altitudinal gradients in order to validate if satellite precipitation products are capable to represent local climate influences. 


\section{REFERENCES}

Behrangi, A., Hsu, K., Imam, B., \& Sorooshian, S. (2010). Daytime precipitation estimation using bispectral cloud classification system. Journal of Applied Meteorology and Climatology, 49(5), 1015-1031.

Ceccato, P. N., \& Dinku, T. (2010). Introduction to Remote Sensing for Monitoring Rainfall, Temperature, Vegetation and Water Bodies.

Feidas, H. (2009). Validation of satellite rainfall products over Greece. Theoretical and Applied Climatology, 99(1-2), 193-216. doi:10.1007/s00704-009-0135-8

Habib, E., Henschke, A., \& Adler, R. F. (2009). Evaluation of TMPA satellite-based research and real-time rainfall estimates during six tropical-related heavy rainfall events over Louisiana, USA. Atmospheric Research, 94(3), 373-388.

Huffman, G. J. (2015). The Transition in Multi-Satellite Products from TRMM to GPM (TMPA to IMERG) (p. 3). Retrieved from http://pmm.nasa.gov/sites/default/files/ document_files/TMPAto-IMERG_transition.pdf

Huffman, G. J., Bolvin, D. T., Nelkin, E. J., Wolff, D. B., Adler, R. F., Gu, G., Stocker, E. F. (2007). The TRMM multisatellite precipitation analysis (TMPA): Quasi-global, multiyear, combined-sensor precipitation estimates at fine scales. Journal of Hydrometeorology, 8(1), 38-55.

Kidd, C., Levizzani, V., \& Laviola, S. (2011). Quantitative precipitation estimation from Earth observation satellites. Rainfall: State of the Science, 127-158.

Muñoz, Á. G., Lopez, P., Velasquez, R., Monterrey, L., Leon, G., Ruiz, F., Urdaneta, A. (2010). An Environmental Watch System for the Andean countries: El Observatorio Andino. Society, 91(dEcEmbEr), 20.

NASA. (2014a). TRMM 3B43. doi:10.1175/JHM560.1

NASA. (2014b). TRMM 3B43 Dataset. Retrieved October 07, 2014, from http://disc.sci.gsfc.nasa.gov/precipitation/ documentation/TRMM_README/TRMM_3B43_readme.shtm 1

Ochoa, A., Pineda, L., Crespo, P., \& Willems, P. (2014). Evaluation of TRMM 3B42 precipitation estimates and WRF retrospective precipitation simulation over the Pacific-Andean region of Ecuador and Peru. Hydrology and Earth System Sciences, 18(8), 3179-3193. doi:10.5194/hess-18-3179-2014

Schaefer, J. T. (1990). The Critical Success Index as an Indicator of Warning Skill. Weather and Forecasting, 5(4), 570-575. doi:10.1175/1520-0434(1990)005\%253C0570:

TCSIAA\%253E2.0.CO;2

Scheel, M. L. M., Rohrer, M., Huggel, C., Santos Villar, D., Silvestre, E., \& Huffman, G. J. (2011). Evaluation of TRMM Multi-satellite Precipitation Analysis (TMPA) performance in the Central Andes region and its dependency on spatial and temporal resolution. Hydrology and Earth System Sciences, 15(8), 2649-2663. doi:10.5194/hess-15-2649-2011

Simpson, J., Adler, R. F., \& North, G. R. (1988). A proposed tropical rainfall measuring mission (TRMM) satellite. Bulletin American Meteorological Society, 69(3), 278-295.
Su, F., Hong, Y., \& Lettenmaier, D. P. (2008). Evaluation of TRMM Multisatellite Precipitation Analysis (TMPA) and Its Utility in Hydrologic Prediction in the La Plata Basin. Journal of Hydrometeorology, 9(4), 622-640. doi: 10.1175/2007JHM944.1

Wang, X., \& Feng, Y. (2004). RHTest user manual. at Http://cccma. Seos. Uvic. ca/ETCCDMI/RHTest/

Ward, E., Buytaert, W., Peaver, L., \& Wheater, H. (2011). Evaluation of precipitation products over complex mountainous terrain: a water resources perspective. Advances in Water Resources, DOI: 10.10. doi:10.1016/j.advwatres.2011.05.007

Zambrano-Bigiarini, M. (2014). R library hydroGOF: Goodnessof-fit functions for comparison of simulated and observed hydrological time series. Version 0.3-8.

Zulkafli, Z., Buytaert, W., Onof, C., Manz, B., Tarnavsky, E., Lavado, W., \& Guyot, J.-L. (2014). A Comparative Performance Analysis of TRMM 3B42 (TMPA) Versions 6 and 7 for Hydrological Applications over Andean-Amazon River Basins. Journal of Hydrometeorology, 15(2), 581-592. doi:10.1175/JHM-D-13-094.1 